\title{
Conducting research in the time of pandemic: A pause or an opportunity?
}

\author{
Alison Castro Superfine ${ }^{1}$ \\ Published online: 28 August 2020 \\ (c) Springer Nature B.V. 2020
}

The global pandemic has presented a variety of challenges, including physically, emotionally, financially, and much more, the effects of which are only beginning to be felt. Researchers and educators at universities, colleges, and primary and secondary schools face specific and ongoing challenges related to the pandemic. In our roles as researchers and educators, these challenges are manifested in our abilities to conduct education research in school and university classrooms, supervise students in clinical settings, and for some, in the need to teach courses online (for those not already accustomed to or experienced in doing so). For many, these circumstances have required us to be agile and flexible in our approaches to teaching, the ways in which we interact with colleagues and students in our classes, and to innovate in the ways we carry out our research activities. The need for high-quality research that can serve as a source of reliable information, innovation, and "know-how" that is shared through means such as this journal is stronger than ever.

So, what is the role of education research in helping the research community navigate such challenges? In my own work, for example, I found myself reaching out to colleagues for ideas as to how to transition my courses to online environments. I have begun to actively seek out research articles in journals to learn about design principles for online teaching and learning and for research on the effectiveness of various strategies for promoting collaboration and productive disciplinary discourse in synchronous online environments.

However, I found very few ideas or examples for how to carry out research activities when the settings and contexts in which these activities are carried out are no longer available in the form in which the research activities were originally conceived. Indeed, I directly needed to address how one continues to carry out research activities, particularly those activities that are funded by external agencies or organizations that may have certain requirements and restrictions as to how and when the research funds are to be utilized. Initially, I anticipated that many research articles that reported on any research collected during 2020-2021 would have an asterisk next to it (e.g., Year 1, Year 2*, Year 3), with the shared understanding that the global pandemic caused a disruption in the data collection in that year, in many cases a complete stoppage. However, after several conversations with colleagues, I came to realize that the current global pandemic has presented an opportunity for researchers to reconceptualize how to continue data collection in line with the goals of their research, but under the constraints that the pandemic has presented—an opportunity

Alison Castro Superfine

amcastro@uic.edu

1 University of Illinois at Chicago, Chicago, US 
as opposed to a challenge. While it may be too early for research studies to come out in journals that describe their efforts navigating university- and school-based data collection efforts in the time of pandemic, over the next year or so I imagine there will be a steady stream of research articles that describe the shifts that researchers took in reconceptualizing their data collection protocols during this time.

For example, in my own research projects in the USA, one of the many data sources we have been collecting are in-person, school-based classroom observations of teachers as a measure of mathematics instruction. However, with much of the instruction in our partner schools moved entirely online with a combination of synchronous and asynchronous work, conducting in-person, school-based classroom observations is no longer feasible. Moreover, the prospect of "observing" an online class session in its place is not feasible as well. Aside from the myriad of privacy concerns such online observation raises (e.g., cameras in students' and teachers' homes), the reality is that many teachers are not accustomed to teaching online, nor or many schools prepared to support remote instruction or have the resources and technological infrastructure to support widespread remote learning for its constituents. It is not normal for many, to say the least. So, how can we obtain a valid understanding of instruction under these circumstances? One possibility that we are currently discussing among my research team is the idea of collecting artifacts of practice that, in the absence of in-person, school-based observations, may provide insight into instruction. Such artifacts might include teachers' lesson plans, and copies of tasks or activities provided to students. We would then need to analyze these artifacts in ways that are closely tied to the various dimensions of the classroom observation instrument we are using. This is not ideal, by any means. However, it is an attempt to "take the temperature" on the nature of instruction during difficult circumstances, all while being sensitive to the needs of teachers, students, and schools, and maintaining and nurturing the close partnerships we have with our school partners.

I am hopeful that we as a global research community will be able to weather this storm and come out on the other side more knowledgeable and agile than before. I am equally as hopeful that journals such as this one can continue to serve as a source of information and innovation for our ideas. The articles in this issue of JMTE are no exception. The global pandemic does not mean we have to put a pause on our research activities, but rather presents an opportunity for us as researchers to align our ongoing work with the changing and pressing realities of schools and classrooms in real time.

The articles in this issue discuss a range of pedagogical tools and learning configurations and propose conceptualizations of teacher beliefs and teaching expertise, all of which have implications for teacher professional learning. For example, Lutovac and Kaasila use bibliotherapy as a pedagogical tool in mathematics education courses for prospective teachers. Bibliotherapy involves the use of different types of readings (e.g., personal narratives, research articles, biographies) that are used to promote affective change in individuals over time, including minimizing mathematics anxiety. The authors analyzed the ways in which prospective teachers identified with different types of readings used in their courses to inform their work as teacher educators in making selections of readings that might be most optimal for promoting affective change in prospective teachers. In their study, they found that prospective teachers identified with readings that included descriptions of a negative experience in mathematics, as well as stories of individuals' challenges faced and ways in which they coped with the challenges. The authors conclude with implications for the use of bibliotherapy in teacher education courses.

Larina and Markina investigate secondary teachers' beliefs about students' abilities in school. Using individual interviews from 30 teachers, the authors articulate a continuum of 
teacher beliefs with one end representing what the authors refer to as an exclusive model of beliefs and the other end as an inclusive model. While an exclusive model of teacher beliefs depicts students' abilities as fixed and including certain characteristics that describe what teachers consider to be a "normal" student, an inclusive model depicts students' abilities as diverse and specific to students as individuals. Teachers in their study exhibited a range of beliefs, including those that had mixed features of both exclusive and inclusive belief models, as well as teachers who exhibited largely exclusive or inclusive features of beliefs about students' abilities.

Drawing from survey and observation data from the National Center for Teaching Effectiveness, Auletto and Stein focus on identifying teaching expertise in classroom observations and its relationship to students' experiences in classrooms. Using the CLASS observation instrument, they conceptualize teaching expertise as the observable ways that teachers draw on their mathematical understanding to engage in content-focused conversations with students during instruction. Overall, they found that teachers' expertise predicts the extent to which students learn mathematics. They also found that teachers' expertise predicted various socioemotional outcomes in students, including students' reported selfefficacy in mathematics and students' perception of caring relationships with their mathematics teachers. They conclude by discussing the implications of their findings for teacher professional development.

Finally, Lloyd et al. explore different configurations in which researchers and prospective teachers can collaborate, namely through the use of triads. In particular, they focus on the learning of individuals within student-teaching triads that consist of an intern/prospective teacher, a mentor teacher, and a university supervisor. They focus on the professional learning of individuals and opportunities for professional learning that emerge as part of the joint work in the triads over time. Using individual and joint interviews with members of different triads, the authors found that participants reported learning in the areas of pedagogical knowledge and practices for teaching mathematics, and for some, learning knowledge of mathematics for teaching as a result of the joint work. Notably, there were differences in the reported usefulness of talking with the triads as an opportunity for professional learning.

I am hopeful that the articles in this issue offer a range of pedagogical tools, conceptualizations, and examples of different learning configurations that can serve as innovation and "know-how" to this community as we carry out our work in these uncertain times.

Publisher's Note Springer Nature remains neutral with regard to jurisdictional claims in published maps and institutional affiliations. 